Discourse and Communication for Sustainable Education, vol. 8, no. 1, pp. 129-144, 2017

\title{
Student Socioeconomic Status and Teacher Stroke: A Case of Female Students in Iran
}

\author{
Fatemeh Irajzad and Hesamoddin Shahriari \\ Ferdowsi University of Mashhad, Iran
}

\begin{abstract}
Supportive teacher-student relationships play a significant role in the trajectory of students' academic life. Teachers may use various strategies to improve this relationship, one of which is teacher stroke (teacher encouragement). The stroking behavior of teachers might be influenced by several factors, including the socioeconomic status (SES) of students. Accordingly, the current study aims to investigate the differences among female English language teachers at three different school districts (i.e., upper, middle, and lower socio-economic class) in Mashhad, Iran, with regard to their stroking behavior. To fulfill this aim, 300 eighth-grade female students responded to an 18-item questionnaire and the collected data were subsequently analyzed using a one-way ANOVA. The results revealed that teachers tend to stroke high-SES students more frequently. The second aim of this study was to find out if there is a significant correlation between teacher stroke and students' GPA. The results indicated that all the sub-components of stroke significantly correlate with students' GPA. Moreover, the results of a stepwise multiple regression test indicated that two of the sub-components of stroke, namely valuing and classroom activities, strongly predict students' GPA. Finally, the findings of the study have been discussed in light of the existing literature and implications have been provided for language teaching in the formal context of education.
\end{abstract}

Keywords: English school teachers, female students, stroking behavior, student GPA, student SES, sustainability.

\section{Introduction}

There are many factors which influence the formal schooling experience of students, one of which is the quality of teacher-student relationships (Murray \& Malmgren, 2005). In fact, several studies have shown that supportive teacher-student relationships make students more satisfied with school experience and create a feeling of security in the classroom environment (Baker, Grant, \& Morlock, 2008; Fischer, et al., 2015). To be more precise, if teachers create a positive learning atmosphere in the class, students become more academically engaged (Marks, 2000; Williams, Edwards, Kuhel, \& Lim, 2016); therefore, they are more likely to earn higher grades (Willingham, Pollack, \& Lewis, 2002) and consequently, have lower drop-out rates (Croninger \& Lee, 2001). 
Hence, there is a relationship between teacher care and engagement on the one hand, and engagement and academic success on the other (Wentzel \& Asher, 1995). Springing from this fact, several studies have been conducted in order to discover the factors which influence teacher-student interactions. Among these factors are teacher immediacy (e.g., Barclay, 2012; Mehrabian, 1967), teacher care (e.g., McBee, 2007; Mercado, 1993; O'Connor, 2008; Wentzel, 1997), teacher effectiveness (e.g., Black \& HowardJones, 2000; Cheung, Cheng, \& Pang, 2008), and emotional intelligence (Hashemi, 2008).

Another factor that can potentially have a positive impact on the quality of teacherstudent relationships is 'stroke'. Widely known as an important component of teacher care, stroke is simply defined as a unit of human recognition (Berne, 1988). In other words, the stroker (e.g., a teacher) recognizes the strokees (e.g., students) through recalling their names, respecting their opinions, maintaining eye contact, etc. Despite its significance in human beings' social lives, stroke is infrequent and this presumably springs from a restrictive economy of stroke which inhibits people from generously stroking each other (Steiner, 1997).

Although research on stroke has been slow to emerge, the topic has recently attracted more attention from academics (e.g., Pishghadam \& Khajavy, 2014; Yazdan Pour, 2015; Hosseini, 2016; Namaghi, 2016; Irajzad, Pishghadam, \& Shahriari, 2017). These studies have investigated various aspects of stroke in the educational setting; however, no study has yet looked at the impact of SES on the amount of teacher stroke and the nature of teacher-student relationships. Therefore, to fill this empirical gap, the current study seeks to examine the correlation between students' SES and teacher stroke. It is noteworthy that previous studies (e.g., Entwisle \& Alexander, 1988; Hamre \& Pianta, 2001; Parker, 2013) have indeed explored the impact of students' SES on teacher-student relationships; however, this study focuses on stroke as one particular aspect of teacherstudent relationships.

SES is typically broken down into three classes, namely high, middle, and low SES. In this study, the students' SES has been determined based on their school district. As an indicator of SES, school district reflects the social and economic resources available to students (Sirin, 2005). Hence, teachers in each school district may have a particular perception of their students, which may in turn influence their stroking behaviors.

Another aim of this study was to explore the relationship between teacher stroke and students' GPA. As mentioned earlier, positive teacher-student relationships could possibly improve the students' GPA (Willingham et al., 2002; Murray \& Malmgren, 2005). The investigation of these issues in the Iranian educational context is of particular significance and the findings may potentially lead to insightful educational implications.

Accordingly, this research is designed to address the following questions:

(1) Does students' SES have an impact on the stroking behavior of English language teachers?

(2) Is there a significant correlation between students' GPA and teacher stroke?

(3) Can the sub-components of stroke strongly predict students' GPA? If so, which sub-component best predicts students' GPA? 


\section{Review of the Related Literature}

\section{Teacher Care and Teacher Stroke}

Teaching and learning are social practices which depend heavily on emotional experiences (Hargreaves, 1994; Timostsuk, 2016). In fact, the school context creates an environment with a variety of positive/negative emotional experiences, each of which have the potential to influence learning, teaching, and motivational processes (Goldstein, 1999). According to Roffey (2012), positive feelings are pivotal for the resilience and wellbeing of students. Hence, emotions are an integral part of educational settings and providing a caring classroom environment is of great importance. One source of positive feelings in the classroom environment is teacher care. Teacher care includes teacherinitiated practices that foster strong relationships with the students (Rogers \& Webb, 1991). In fact, teachers can promote positive emotions in the classroom by engaging their students in meaningful activities, providing an environment which encourages students' participation in classroom discussions, respecting the students, and showing empathy (Weinstein, 1998; Gedzune, 2015). As asserted by Kohl (1984), teachers are obligated to care about all their students. If a teacher does not treat all students equally, biased relationships with students would take place (Gomez, Allen, \& Clinton, 2004). The unequal allocation of teacher's attention has many reasons, one of which may be the students' socio-economic status.

Teachers have a central role in shaping a supportive relationship with students. In this way, they can boost students' motivation and help them promote their interpersonal skills (Pierson, 2003). Teacher-student relationships could be examined using Transactional Analysis (TA) theory proposed by Berne (1988). Stewart and Joines (1987) defined TA as a "theory of personality and systematic psychotherapy for personal growth and personal change" (p. 3). Transactional Analysis theory consists of six basic components, including ego states, life positions, life scenario, transactions, time structures, and strokes (Berne, 1988). This theory has been broadly applied in psychology, counseling, communication, and education (Solomon, 2003). With regard to education, TA theory provides a solid basis for perceiving the links between human behaviors, education, and learning (Barrow \& Newton, 2015). High awareness of the TA theory may also bring about a supportive relationship between teachers and learners (Stewart \& Joines, 1987). Furthermore, its application in educational settings would lead to positive changes in the education process and result in a more natural learning process (Stuart \& Alger, 2011). Therefore, due to its significance, several scholars have investigated the benefits of using TA in the classroom context in particular and the school as a whole (e.g., Barrow, Bradshaw, \& Newton, 2001; Hellaby, 2004).

The concept of stroke is one of the six components of TA theory and a major component of teacher care (Pishghadam, Naji Meidani, \& Khajavy, 2015), and it is defined as any action to recognize the presence of others (Shirai, 2006). According to Berne (1988), providing people with strokes satisfies their need for recognition. Different categories of stroke are verbal/non-verbal, positive/negative, and/or conditional/unconditional (Stewart \& Joines, 1987). Verbal strokes (e.g., saying hi) deal with an exchange of spoken words, whereas non-verbal strokes involve actions such as waving and nodding; positive strokes (e.g., you look great) give the feeling of satisfaction to the addressee, while negative strokes (e.g., I hate you) make the addressee feel displeased; conditional strokes (e.g., you arelare not a good actor) are about what we do, and unconditional strokes (e.g., I love you; I hate you) are about what we are (Stewart \& Joines, 1987). 
According to Francis and Woodcock (1996), motivating others may be achieved either by positive reinforcement or negative reinforcement. The former type of reinforcement refers to strokes which aim to highlight positive behavior and the latter refers to providing negative strokes to encourage better performance and minimize errors. From this perspective, motivation and stroke are closely connected. Since stroking rewards the behavior being stroked, that specific behavior would likely be reinforced (Stewart $\&$ Joines, 1987). Therefore, stroke is also related to the concept of feedback. As suggested by Hattie and Timperley (2007), the kind of feedback that provides evaluation (either positive or negative) directed at the students is closely related to stroke.

Recently, scholars have looked at stroke from several perspectives and examined its relationship with different educational factors. More specifically, Pishghadam and Khajavy (2014) found a significant positive relationship between stroke and student motivation. In another study, Yazdan Pour (2015) validated a teacher stroke scale and investigated the relationship between stroke and teacher burnout. The findings of this study indicated a negative correlation between stroke and teacher burnout.

In the same vein, Namaghi (2016) investigated the impact of teacher stroke on the willingness of students to attend school and found that two of the sub-components of stroke (i.e., nonverbal and valuing) are of particular significance in this regard. In an attempt to explore English language teachers' conceptions of stroke, Hosseini (2016) conducted a qualitative study, the findings of which suggested that teachers are aware of different types of stroke, but do not know how to stroke freely and appropriately. In a recent study, Irajzad, et al. (2017) conducted a mixed-methods study which investigated the differences among English, Persian, and Arabic school teachers in Iran with regard to their stroking behaviors.

\section{Socioeconomic Status (SES)}

Socioeconomic status is the most frequently-used contextual variable in educational research (Sirin, 2005). To measure SES, a number of factors have to be determined. The bulk of research on this topic has shown that the most common factors indicating SES are income, education, and occupation (Brooks-Gunn \& Duncan, 1997; Milne \& Plourde, 2006; Sirin, 2005). It is noteworthy that SES can also be determined by factors such as school location and students' characteristics (Sirin, 2005).

In this regard, researchers need to decide whether to use an individual student's SES or an aggregated SES based on the neighborhood in which they reside (BrooksGunn \& Duncan, 1997) or their school district (Caldas \& Bankston, 1997). According to Sirin (2005), school and neighborhood SES indicators share the underlying meaning of SES as a contextual indicator of social and economic well-being. Therefore, school district is closely linked to the social and economic condition of students (Sirin, 2005). The National Assessment of Educational Progress (NAEP) reported that the academic achievement of students in rich suburban schools was significantly higher than the students in poor urban schools (U.S. Department of Education, 2000). In fact, low SES is highly correlated with low academic achievement (Milne \& Plourde, 2006). Therefore, in order to help low-SES students achieve higher academic potentials; teachers' role is of paramount significance (Gustafson, 2002). 


\section{Methodology}

\section{Participants}

The participants of this study consisted of 300 eighth-grade female students at six high schools located in the upper-class, middle-class, and lower-class school districts of Mashhad, Iran. Three schools were selected from each district. The criterion for dividing Mashhad into three socio-economic classes was based on the guidelines provided by the Education Department of Khorasan-e-Razavi. The researchers asked the Department of Education for permission to collect data from schools located in three districts of Mashhad. The Department of Education recommended district five (low-class), district seven (middle-class), and district three (upper-class). Since the education department only allowed access to a limited number of schools, convenience sampling was used.

\section{Instrumentation}

To evaluate teacher stroke, the Student Stroke Scale (SSS) was used. This scale has been constructed and validated by Pishghadam and Khajavi (2014). Since statistical procedures have confirmed the validity of SSS as a measure of stroke, it can be used in all educational settings. The SSS consists of 18 items which are designed to assess verbal, non-verbal, positive, and negative strokes on a five-point Likert-type scale ranging from 1 (never) to 5 (always). The reliability of the whole set of items is 0.86 .

The items of this scale are categorized under four sub-components, namely verbal, non-verbal, valuing, and classroom activities. For better illustration, the sub-components and their corresponding items have been presented in Table 1.

Table 1

The Subcomponents of Stroke and Their Corresponding Items

\begin{tabular}{|c|c|c|c|c|}
\hline \multirow[b]{2}{*}{ Questionnaire Items } & \multicolumn{4}{|c|}{ Components of stroke } \\
\hline & Verbal & $\begin{array}{l}\text { Non- } \\
\text { verbal }\end{array}$ & Valuing & $\begin{array}{l}\text { Classroom } \\
\text { Activities }\end{array}$ \\
\hline 1-Teacher knows my name. & $*$ & & & \\
\hline 2-Teacher mentions my name in the classroom. & $*$ & & & \\
\hline 3-Teacher encourages me. & $*$ & & & \\
\hline 4-Teacher blames me. & $*$ & & & \\
\hline 5-Teacher compliments me in front of the others. & $*$ & & & \\
\hline 6-Teacher asks me questions. & $*$ & & & \\
\hline 7-Teacher smiles at me in the classroom. & & $*$ & & \\
\hline 8-Teacher frowns at me. & & $*$ & & \\
\hline 9-Teacher looks at me. & & $*$ & & \\
\hline 10-Teacher pays attention to me. & & $*$ & & \\
\hline $\begin{array}{l}\text { 11-Teacher devotes enough time to me outside the } \\
\text { classroom. }\end{array}$ & & & * & \\
\hline $\begin{array}{l}\text { 12-Teacher devotes enough time to me in the } \\
\text { classroom. }\end{array}$ & & & $*$ & \\
\hline $\begin{array}{l}\text { 13-Teacher uses my personal experience in the } \\
\text { classroom. }\end{array}$ & & & $*$ & \\
\hline
\end{tabular}


Sequel to Table 1.

14-Teacher uses my scientific knowledge in the classroom.

15 -Teacher pays attention to my homework.

16-Teacher uses me for doing the exercises.

17-Teacher uses me in class discussions.

18-Teacher lets me ask questions.

\section{Procedure}

After going through the administrative process for choosing three school districts, the researchers started the process of data collection. The first step was to obtain the consent of teachers for distributing the questionnaires in their classes. Before handing out the questionnaires, the students were told not to write their names on the questionnaire sheets.

In order to analyze the questionnaire data and address the research questions, a number of statistical tests including the Pearson correlation test, stepwise multiple regression, and one-way ANOVA were used.

\section{Results}

In order to address the first research question, one-way between-groups ANOVA was conducted. The descriptive statistics displayed in Table 2 provide the information required for the analysis of all the dependent variables across three levels.

Table 2

Descriptive Statistics for the Dependent Variables across the Three Levels

\begin{tabular}{|c|c|c|c|c|c|c|c|}
\hline & & $\mathrm{N}$ & Mean & Std. Deviation & Std. Error & Min & $\operatorname{Max}$ \\
\hline \multirow[t]{4}{*}{ nonverbal } & upper & 100 & 3.37 & .55 & .05 & 2.00 & 4.75 \\
\hline & mid & 100 & 3.10 & .68 & .06 & 1.50 & 4.25 \\
\hline & lower & 100 & 3.09 & .55 & .05 & 1.75 & 4.50 \\
\hline & Total & 300 & 3.18 & .61 & .03 & 1.50 & 4.75 \\
\hline \multirow[t]{4}{*}{ verbal } & upper & 100 & 3.30 & .64 & .06 & 1.33 & 4.33 \\
\hline & mid & 100 & 3.01 & .82 & .08 & 1.33 & 4.67 \\
\hline & lower & 100 & 3.25 & .65 & .06 & 1.67 & 5.00 \\
\hline & Total & 300 & 3.19 & .72 & .04 & 1.33 & 5.00 \\
\hline \multirow[t]{4}{*}{ classroom } & upper & 100 & 4.19 & .81 & .08 & 1.50 & 5.00 \\
\hline & mid & 100 & 3.80 & .97 & .09 & 1.50 & 5.00 \\
\hline & lower & 100 & 4.19 & .81 & .08 & 1.50 & 5.00 \\
\hline & Total & 300 & 4.06 & .88 & .05 & 1.50 & 5.00 \\
\hline \multirow[t]{4}{*}{ valuing } & upper & 100 & 3.20 & .98 & .09 & 1.00 & 5.00 \\
\hline & mid & 100 & 2.71 & 1.04 & .10 & 1.00 & 5.00 \\
\hline & lower & 100 & 2.92 & 1.07 & .10 & 1.00 & 4.75 \\
\hline & Total & 300 & 2.94 & 1.04 & .06 & 1.00 & 5.00 \\
\hline
\end{tabular}


Sequel to Table 1.

\begin{tabular}{cccccccc}
\hline total & upper & 100 & 3.49 & .60 & .06 & 1.72 & 4.56 \\
\cline { 2 - 8 } & mid & 100 & 3.14 & .72 & .07 & 1.72 & 4.56 \\
\cline { 2 - 8 } & lower & 100 & 3.35 & .61 & .06 & 1.83 & 4.61 \\
\cline { 2 - 8 } & Total & 300 & 3.32 & .66 & .03 & 1.72 & 4.61 \\
\hline
\end{tabular}

The results of Levene's test reveal that except for valuing and total variables, the significance value of the three other dependent variables violated the assumption of homogeneity of variances. Therefore, the Welch test was used as an alternative statistical solution for the first, second and third dependent variables, whereas one-way ANOVA was employed for the other variables.

\section{Welch Test}

Based on the results of the Welch test, there are significant differences among the three groups of teachers in terms of nonverbal $F(2,196.294)=7.526, p<0.05$, verbal $F(2,195.979)=3.908, p<0.05$, and classroom $F(2,196,754)=6.061, p<0.05$ strokes.

\section{ANOVA}

The results of the ANOVA test indicated a significant difference among the three groups of teachers in terms of valuing $\left(F(2,297)=5.620, p<.05, \eta^{2}=.03\right)$ and total $\left(F(2,297)=7.435, p<.05, \eta^{2}=.04\right)$ strokes. Having found statistically significant differences, a post hoc test had to be conducted to determine which subgroup means differ from the others.

\section{Post hoc Tests}

The Games-Howell post hoc test was conducted for the dependent variables with unequal variances (namely nonverbal, verbal, and classroom) and Tukey post hoc test was used for the other dependent variables (i.e., valuing and total).

\section{Games-Howell Test}

As for nonverbal stroke, the results indicated that the mean score for teachers of upper-class schools $(\bar{x}=3.3700, S D=.55673)$ is significantly different from that of middle-class schools $(\bar{x}=3.1025, S D=.68819)$ and lower-class schools $(\bar{x}=3.0925$, $S D=.55352)$. However, teachers of middle-class and lower-class schools do not differ significantly in this regard (To summarize: upper > lower/mid).

With regard to verbal stroke, the results revealed that the mean score for teachers of upper-class schools $(\bar{x}=3.3000, S D=.64571)$ is significantly different from that of middle-class schools $(\bar{x}=3.0167, S D=.82555)$. However, the mean score for teachers of upper-class schools is not significantly different from that of lower-class schools $(\bar{x}=3.2533, S D=.65968)$. Additionally, the mean scores for teachers of middle-class schools and lower-class schools do not differ significantly (To summarize: upper $>$ mid).

With regard to classroom stroke, the results indicated that the mean score for teachers of upper-class schools $(\bar{x}=4.1975, S D=.81130)$ is significantly different from 
that of middle-class schools $(\bar{x}=3.8000, S D=.97247)$. Also, the mean score for teachers of middle-class schools is significantly different from that of lower-class schools $(\bar{x}=4.1900, S D=.81194)$. However, teachers of upper-class schools and lower-class schools did not differ significantly (To summarize: upper/lower $>$ mid).

\section{Tukey HSD Test}

The findings of this study with regard to the valuing stroke indicated that the mean score for teachers of upper-class schools $(\bar{x}=3.2000, S D=.98088)$ is significantly different from that of middle-class schools $(\bar{x}=2.7125, S D=1.04045)$. However, the mean score for teachers of upper-class schools is not significantly different from that of teachers in lower-class schools $(\bar{x}=2.9200, S D=1.07243)$. Also, the mean scores for teachers of middle-class schools and lower-class schools do not differ significantly (To summarize: upper $>$ mid).

As for the total stroke variable, the results indicated that the mean score for teachers of upper-class schools $(\bar{x}=3.4928, S D=.60171)$ is significantly different from the teachers of middle-class schools $(\bar{x}=3.1422, S D=.72014)$. However, the mean score for teachers of upper-class schools is not significantly different from that of lower-class schools $(\bar{x}=3.3517, S D=.61211)$. Also, the mean scores for teachers of middle-class schools and lower-class schools do not differ significantly (To summarize: upper $>$ mid).

\section{Correlation}

As for the second research question, the results revealed that all the sub-components of stroke (nonverbal $r=.148, p<0.05$; verbal $r=.194$, $p<0.05$; classroom activities $r=.238, p<0.05$; valuing $r=.253, p<0.05)$ and total stroke $(r=.258, p<0.05)$ are significantly correlated with GPA. This implies that receiving strokes significantly influences students' GPA.

\section{Stepwise Multiple Regression}

Based on the results of stepwise multiple regression test, only valuing and classroom variables passed the entry test of an $F$ with an associated probability level of .05 ; hence, these two variables were included in the analysis.

Table 3

Model Summary of Regression Analysis for GPA

\begin{tabular}{ccccl}
\hline Model & $\mathrm{R}$ & Adjusted $\mathrm{R}^{2}$ & Std. Error of the Estimate & \multicolumn{1}{c}{$\mathrm{B}$} \\
\hline 1 & $.253^{\mathrm{a}}$ & .062 & 1.35107 & .253 \\
2 & $.274^{\mathrm{b}}$ & .071 & 1.34451 & .172 (valuing) \\
& & & & .133 (class) \\
\hline
\end{tabular}
a. Predictors: (Constant), valuing
b. Predictors: (Constant), valuing, classroom

According to the model summary, the regression equation is significant in the first model $(F(1,498)=34.158, p<.05)$. Hence, the valuing variable accounts for $6 \%$ of the 
total GPA variance (Adjusted $R^{2}=.062$ ). Also, Beta coefficients show that the relationship between valuing and GPA is positive and significant $(B=.253, p<.05)$.

In the second model, the regression equation is significant, $F(1,498)=5.869$, $p<.05$. This indicates that the first and second variables (i.e., valuing and classroom) account for $7 \%$ of the variance of GPA. Moreover, Beta coefficients reveal that there is a significant positive correlation between valuing stroke and GPA $(B=.172, p<.05)$, and the relationship between classroom stroke and GPA is also positive $(B=.133$, $p<.05)$. In other words, valuing and classroom strokes are the best predictors of the students' GPA.

\section{Discussion}

With regard to the first research question, the results indicate that in three of the four sub-components of stroke (i.e., nonverbal, verbal, and valuing), the English teachers of upper-class schools ranked first. This finding is consistent with the findings of Entwisle and Alexander (1988) and Hamre and Pianta (2001) who have also reported that students with high SES enjoy more supportive relationships with their teachers. According to Parker (2013), students' SES may have a direct impact on their relationships with teachers. There are some lines of explanation for this finding.

Parents' involvement in the education process of their children positively influences the teacher-student relationship (Patrikakou, 2008; Kazlauskiene, Gaucaite, \& Juodaityte, 2011). As several scholars have noted (e.g., Entwisle \& Alexander, 1988; Hamre \& Pianta, 2001), close parent-teacher relationships appear to be more common among families with higher SES. Indeed, parental involvement is a positive source of influence for the academic achievement of students and it has a critical role in the children's academic motivation and engagement (Reynolds, 1991). Examples of parental involvement behavior include providing financial aids to the school, volunteering in school events, communicating with the teacher, attending school gatherings, and monitoring their child's experiences at school (Hughes \& Kwok, 2007). Since these parents devote a lot of time and energy to their child's education, they have higher expectations from the school staff, mainly teachers, to provide better educational services for their children. Therefore, high-SES pupils do better at school because parents and school staff put more effort into their education. Also, the positive influence of parents on school events and other decision-making activities raises the self-confidence of their children who would then find the courage to be more active in the classroom; as a result, teachers stroke these students more frequently. Furthermore, teachers' perceptions of parents and their children will be influenced by the parents' level of education, job, etc. (Patrikakou, 2008). Consequently, teachers may have more positive attitudes toward students with educated and affluent parents.

Another factor which influences the stroking behavior of teachers is the cultural capital of high-SES students. Dumais (2002) argued that within the educational field, the most valuable form of capital is cultural capital which depends largely on one's social class (Dumais, 2002). In fact, cultural capital is "a broad knowledge of culture that belongs to members of the upper classes and is found much less frequently among the lower classes" (Dumais, 2002, p. 44). Coming from upper-class families, high-SES students have been exposed to different realizations of cultural capital since their childhood. As a result, they feel more comfortable in school and communicate more easily with their 
teachers (De Graaf, De Graaf, \& Kraaykamp, 2000). It is worth mentioning that cultural capital serves as a signal to teachers (who probably have a high respect for culture) that they will establish better relationships with these students (DiMaggio, 1982).

Classroom features (e.g., educational facilities, class size) is another factor affecting teacher stroke. As a matter of fact, schools in rich neighborhoods have better facilities and less crowded classes. Therefore, teachers at these schools can pay more attention to students and establish better relationships with them. A study conducted by Blatchford (2003) revealed that students in less crowded classes are more often the focus of teacher's attention, whereas students in crowded classes seem to have a passive role. According to what has been stated so far, students with high SES have better chances of receiving strokes from their teachers. Also, teachers at upper-class schools are more likely to establish positive relationships with the students.

Regarding classroom activities, the results of this study indicated that teachers of upper-class schools share the first rank with teachers of lower-class schools, while teachers of middle-class schools ranked lower, a finding which implies that students of upper and lower-class schools are more involved in classroom activities.

The previously-mentioned factors explain why students with high SES are more likely to receive strokes from their teachers.

Low-SES students lack access to most of the resources, experiences and learning materials available to students in upper-class schools (Brooks-Gunn \& Duncan, 1997). More specifically, they are less likely to travel, attend English classes, or experience activities that enhance their skills. Due to the lack of access to such cultural resources, low-SES students "find the school environment different from their home environment and lack the capital [cultural capital] necessary to fit in as well as the higher-SES students" (Dumais, 2002, p.46); therefore, these students often lag behind academically. Moreover, low-SES parents do not often participate in school activities and have less positive interactions with teachers (Boethel, 2003). In most cases, low-SES parents do not even know the name of their child's teacher (Jensen, 2009). These students have lower expectations as well as lower intrinsic motivation (Caldwell \& Ginther, 1996). As a result, they are usually less engaged in classroom activities.

Considering all these factors, low-SES students experience high levels of foreign language (FL) anxiety in the classroom. In such a situation, a motivating factor must exist; otherwise, they will be completely burned out. In their 1996 study, Caldwell and Ginther introduced a number of variables affecting the academic achievement of lowSES students, one of which was teacher motivation. As Love, Stiles, Mundry and Diranna (2008) argue, the learning of every child is the shared responsibility of teachers and parents. Rather than feeling detached, students should feel a sense of belonging to the classroom environment. In this regard, teachers are influential agents who can alter students' perceptions of their own abilities. Therefore, in the current study, teachers might have felt this responsibility and involved low-SES students in classroom activities to raise their motivation.

Regarding the second research question, it was found that all the sub-components of stroke are significantly associated with GPA. This finding is consistent with Wentzel (1998) who indicated that supportive teacher-student relationships are related to multiple aspects of school motivation, including GPA. This is also consistent with the findings of Christophel (1990) which indicated a positive correlation between teacher attention and student achievement. 
With regard to the third research question, the findings reveal that valuing and classroom activities strongly predict students' GPA in the context of Iranian schools. According to Badawy (1980), Middle Easterners can be classified as having collectivistic cultures. In a collective society, people value teamwork and collaboration and are less likely to act independently or allow themselves to stand out from the others (Rohm, 2010). Also, Kramer (1989) claimed that collective cultures may be characterized by centralized decision-making which may lead to expectations of more assertive and less accommodative behaviors toward subordinates. In fact, in a context in which all values are based on selflessness, valuing the students seems to be meaningless.

Due to cultural differences, strokes have unequal weights in different societies. For instance, calling students by their first names may be a weak stroke in American culture, but a strong one in the Iranian context. Having grown up in a collectivist society, Iranian students may not expect their teachers to devote enough time to them inside or outside the classroom, or to use their personal experiences and knowledge in the classroom. Hence, valuing is a weighted stroke in Iran. To be valued in such a context raises students' motivation and consequently, enhances their engagement in classroom activities. Toshalis and Nakkula (2012) believe that students' psychological connection to the school environment and their teachers affects their motivation levels and participatory behaviors. They also claim that feeling welcomed, included, and valued may have a profound effect on students' motivation and engagement in classroom activities and therefore enhance their efforts to accomplish greater achievements. Thus, valuing brings with itself motivation and also engagement in classroom activities.

\section{Conclusion}

This study sought to examine the impact of students' SES on the stroking behavior of English teachers. As the findings suggest, high-SES students are the major strokees of English teachers, while students with mid or low SES do not receive much attention. Since providing strokes positively influences students' GPA, teachers should be more emotionally involved with mid and low-SES students. As the results display, two of the sub-components of stroke, namely valuing and classroom activities, are the main predictors of students' GPA; therefore, they should receive more emphasis in teacher-student interactions.

Considering the close link between students' SES and teacher stroke, school managers and policy makers should employ certain educational policies as well as teacher standards to provide equal educational opportunities for all the students, regardless of their socioeconomic status.

The findings of this study contribute to the current literature on teacher education and serve as a basis for future research into teacher-student relationships. The current study only investigated the stroking behaviors of eighth-grade female English teachers in Mashhad, Iran. Future studies are recommended to explore the impact of students' SES on the stroking behavior of both female and male teachers of different subjects at different educational levels. Also, in order to make the findings more generalizable, future research may include larger samples of students from more school districts. 


\section{References}

Badawy, M. K. (1980). Styles of mid-eastern managers. California Management Review, $22(2), 51-58$.

Baker, J. A., Grant, S., \& Morlock, L. (2008). The teacher-student relationship as a developmental context for children with internalizing or externalizing behavior problems. School Psychology Quarterly, 23(1), 3-15.

Barclay, A. C. (2012). Measuring teacher immediacy and communication competence on student achievement in calculus: A sequential explanatory mixed method design (Doctoral dissertation, Colorado State University). Retrieved from https://dspace. library.colostate.edu/

Barrow, G., Bradshaw, E., \& Newton, T. (2001). Improving behavior and raising selfesteem in the classroom: A practical guide to using transactional analysis. London, UK: David Fulton Publishers.

Barrow, G., \& Newton, T. (Eds.). (2015). Educational transactional analysis: An international guide to theory and practice. London, UK: Routledge.

Berne, E. (1988). Games people play. London, UK: Penguin.

Black, R. S., \& Howard-Jones, A. (2000). Reflections on best and worst teachers: An experiential perspective of teaching. Journal of Research and Development in Education, 34(1), 1-12.

Blatchford, P. (2003). A systematic observational study of teachers' and pupils' behavior in large and small classes. Learning and Instruction, 13(6), 569-595.

Boethel, M. (2003). Diversity: School, family, and community connections. Annual Synthesis. Austin, TX: Southwest Educational Development Laboratory, National Center for Family and Community Schools.

Brooks-Gunn, J., \& Duncan, G. J. (1997). The effects of poverty on children. The Future of Children, 7(2), 55-71.

Caldas, S. J., \& Bankston, C. (1997). Effect of school population socioeconomic status on individual academic achievement. The Journal of Educational Research, 90(5), 269-277.

Caldwell, G. P., \& Ginther, D. W. (1996). Differences in learning styles of low socioeconomic status for low and high achievers. Education, 117(1), 141-147.

Cheung, L. E., Cheng, M. M., \& Pang, K. C. (2008). Building a model to define the concept of teacher success in Hong Kong. Teaching and Teacher Education, 24(3), 623-634.

Christophel, D. M. (1990). The relationship among teacher immediacy behaviors, student motivation, and learning. Communication Education, 39(4), 323-340.

Croninger, R. G., \& Lee, V. E. (2001). Social capital and dropping out of high school: Benefits to at-risk students of teachers' support and guidance. Teachers College Record, 103(4), 548-581.

De Graaf, N. D., De Graaf, P. M., \& Kraaykamp, G. (2000). Parental cultural capital and educational attainment in the Netherlands: A refinement of the cultural capital perspective. Sociology of Education, 73(1), 92-111.

DiMaggio, P. (1982). Cultural capital and school success: The impact of status culture participation on the grades of US high school students. American Sociological Review, 47(2), 189-201.

Dumais, S. A. (2002). Cultural capital, gender, and school success: The role of habitus. Sociology of Education, 75(1), 44-68. 
Entwisle, D. R., \& Alexander, K. L. (1988). Factors affecting achievement test scores and marks of Black and White first graders. Elementary School Journal, 88(1), 449-471.

Fischer, D., Aubrecht, E. L., Brück, M., Ditges, L., Gathen, L., Jahns, M., ... Wellmann, C. (2015). UN global action programme and education for sustainable development: A critical appraisal of the evidence base. Discourse and Communication for Sustainable Education, 6(1), 5-20.

Foster, K. C. (2008). The transformative potential of teacher care as described by students in a higher education access initiative. Education and Urban Society, 41(1), 104126.

Francis, D., \& Woodcock, M. (1996). The new unblocked manager: A practical guide to self-development. Surrey, United Kingdom: Gower Publishing.

Gedžūne, G. (2015). Awakening pre-service teachers to children's social exclusion in the classroom. Discourse and Communication for Sustainable Education, 6(1), 95-109.

Goldstein, L. S. (1999). The relational zone: the role of caring relationships in the coconstruction of mind. American Educational Research Journal, 36(3), 647-673.

Gomez, M. L., Allen, A., \& Clinton, K. (2004). Cultural models of care in teaching: A case study of one pre-service secondary teacher. Teaching and Teacher Education, 20(5), 473-488.

Gustafson, J. P. (2002). Missing the mark for low-SES students. Kappa Delta Pi Record, $38(2), 60-63$.

Hamre, B. K., \& Pianta, R. C. (2001). Early teacher-child relationships and the trajectory of children's school outcomes through eighth grade. Child Development, 72(2), 625-638.

Hargreaves, A. (1994). Changing teachers, changing times. London, UK: Cassell.

Hashemi, M. (2008). On the role of teachers' emotional intelligence on their pedagogical success (Unpublished master's thesis). Tehran, Iran: Allame Tabataba'i University.

Hattie, J., \& Timperley, H. (2007). The power of feedback. Review of Educational Research, 77(1), 81-112.

Hellaby, L. (2004). Teaching TA in the primary school. In G. Barrow \& T. Newton (Eds.), Walking the talk, how transactional analysis is improving behavior and raising self-esteem (pp. 5-16). London, UK: David Fulton Publishers.

Hosseini, S. (2016). EFL teachers' perceptions of stroke and their application in class: A qualitative study (Unpublished Master's thesis). Ferdowsi University of Mashhad, Iran.

Hughes, J., \& Kwok, O. M. (2007). Influence of student-teacher and parent-teacher relationships on lower achieving readers' engagement and achievement in the primary grades. Journal of Educational Psychology, 99(1), 39.

Irajzad, F., Pishghadam, R., \& Shahriari, H. (2017). Examining the Stroking Behavior of English, Persian, and Arabic School Teachers in Iran: A Mixed-methods Study. International Journal of Instruction, 10(1), 219-236.

Jensen, E. (2009). Teaching with poverty in mind: What being poor does to kids' brains and what schools can do about it. Alexandria, Virginia: ASCD publications.

Kazlauskiene, A., Gaucaite, R., \& Juodaityte, A. (2011). Informing society about preschool education and educational support in the context of sustainable development. Discourse and Communication for Sustainable Education, 2, 32-45. 
Kohl, H. (1984). Growing minds. New York, NY: Harper and Row.

Kramer, R. M. (1989). Windows of vulnerability or cognitive illusions: Cognitive processes and the nuclear arms race. Journal of Experimental Social Psychology, 25(1), 79-100.

Lareau, A. (1989). Home Advantage: Social Class and Parental Intervention in Elementary Education. Philadelphia, PA: The Falmer Press.

Love, N., Stiles, K., Mundry, S., \& DiRanna, K. (2008). Unleashing the power of collaborative inquiry: The data coach's guide to improving learning for all students. Thousand Oaks, CA: Corwin Press.

Marks, H. M. (2000). Student engagement in instructional activity: Patterns in the elementary, middle, and high school years. American Educational Research Journal, $37(1), 153-184$.

McBee, R. H. (2007). What it means to care: How educators conceptualize and actualize caring. Action in Teacher Education, 29(3), 33-42.

Mehrabian, A. (1967). Orientation behaviors and nonverbal attitude communication. Journal of Communication, 17(4), 324-332.

Mercado, C.I. (1993). Caring as empowerment: School collaboration and community agency. Urban Review, 25(1), 79-104.

Milne, A., \& Plourde, L. A. (2006). Factors of a low-SES household: What aids academic achievement? Journal of Instructional Psychology, 33(3), 183-194.

Murray, C., \& Malmgren, K. (2005). Implementing a teacher-student relationship program in a high-poverty urban school: Effects on social, emotional, and academic adjustment and lessons learned. Journal of School Psychology, 43(2), 137-152.

Namaghi, F. R. (2016). The influence of stroke on "Willingness to Attend Classes" (WTAC) and foreign language achievement: A case of Iranian EFL learners (Unpublished master's thesis). Ferdowsi University of Mashhad, Iran.

O'Connor, K. E. (2008). You choose to care: Teachers, emotions and professional identity. Teaching and Teacher Education, 24(1), 117-126.

Parker, K. R. (2013). Student-teacher relationships and impacts of goal orientation, personality, socio-economic status, and performance: An examination of those served by project GRAD knoxville (Master's Thesis). Retrieved from http://trace. tennessee.edu/utk_gradthes/1665

Patrikakou, E. N. (2008). The power of parent involvement: Evidence, ideas, and tools for student success. Lincoln, IL: Center on Innovation and Improvement.

Pierson, W. J. (2003). Reflection on the process of learning the work of nurses during practice experiences (Unpublished doctoral dissertation). Simon Fraser University, Canada.

Pishghadam, R., \& Khajavy, G. H. (2014). Development and validation of the student stroke scale and examining its relation with academic motivation. Studies in Educational Evaluation, 43(2), 109-114.

Pishghadam, R., Naji Meidani, E., \& Khajavy, G. H. (2015). Language teachers' conceptions of intelligence and their roles in teacher care and teacher feedback. Australian Journal of Teacher Education, 40(1), 60-82.

Reynolds, A. J. (1991). Early schooling of children at risk. American Educational Research Journal, 28(1), 392-422.

Roffey, S. (2012). Pupil wellbeing - teacher wellbeing: Two sides of the same coin. Educational and Child Psychology, 29(4), 8-17. 
Rogers, D. L., \& Webb, J. (1991). The ethic of caring in teacher education. Journal of Teacher Education, 42(3), 173-181.

Rohm Jr, F. W. (2010). American and Arab cultural lenses. Inner Resources for Leaders, School of Global Leadership \& Entrepreneurship, Regent University: Virginia Beach.

Salite, I. (2015). Searching for sustainability in teacher education and educational research: Experiences from the Baltic and Black Sea Circle Consortium for educational research. Discourse and Communication for Sustainable Education, 6, 2129.

Shirai, S. (2006). How transactional analysis can be used in terminal care. International Congress Series, 1287, 179-184.

Sirin, S. R. (2005). Socioeconomic status and academic achievement: A meta-analytic review of research. Review of Educational Research, 75(3), 417-453.

Solomon, C. (2003). Transactional analysis theory: The basics. Transactional Analysis Journal, 33(1), 15-22.

Steiner, C. M. (1997). Transactional Analysis in the information age. Transactional Analysis Journal, 27(1), 15-23.

Stewart, I., \& Joines, V. (1987). TA today: A new introduction to transactional analysis. Leics, UK: Lifespace Publishing.

Stuart, K., \& Alger, A. (2011). The use of transactional analysis in secondary education: A case study. Teacher Advancement Network Journal, 3(1).

Timostsuk, I. (2016). Primary science teaching- Is it integral and deep experience for students?. Discourse and Communication for Sustainable Education, 7(1), 82-99.

Toshalis, E., \& Nakkula, M. J. (2012). Motivation, engagement, and student voice: The students at the center series. Boston, MA: Jobs for the Future.

U.S. Department of Education, National Center for Education Statistics. (2000). The condition of education 2000, NCES 2000-602. Washington, DC: Government Printing Office.

Useem, E. L. (1992). Middle schools and math groups: Parents' involvement in children's placement. Sociology of Education, 65(4), 263-279.

Weinstein, C. S. (1998). I want to be nice, but I have to be mean: Exploring prospective teachers' conceptions of caring and order. Teaching and Teacher Education, 14(2), 153-163.

Wentzel, K. R. (1997). Student motivation in middle school: The role of perceived pedagogical caring. Journal of Educational Psychology, 89(3), 411-419.

Wentzel, K. R. (1998). Social relationships and motivation in middle school: The role of parents, teachers, and peers. Journal of Educational Psychology, 90(2), 202209.

Wentzel, K. R., \& Asher, S. R. (1995). The academic lives of neglected, rejected, popular, and controversial children. Child Development, 66(3), 754-763.

Williams, D. L., Edwards, B., Kuhel, K. A., \& Lim, W. (2016). Culturally responsive dispositions in prospective mathematics Tteachers. Discourse and Communication for Sustainable Education, 7(2), 17-33.

Willingham, W. W., Pollack, J. M., \& Lewis, C. (2002). Grades and test scores: Accounting for observed differences. Journal of Educational Measurement, 39(1), 1-37.

Yazdan Pour, H. (2015). Constructing and validating a teacher stroke scale and examining its relationship with burnout (Unpublished master's thesis). Ferdowsi University of Mashhad, Iran. 
Correspondence concerning this article should be addressed to Fatemeh Irajzad, Ferdowsi University of Mashhad, Iran. Email: Fa.irajzad@alumni.um.ac.ir; Hesamoddin Shahriari, Department of English Language and Literature, Faculty of Letters and Humanities, Ferdowsi University of Mashhad (FUM), Azadi Sq., Mashhad, Khorasan Razavi, Iran. Email: h.shahriari@um.ac.ir 